modèles socio-politiques américains ou russes. Face a l'économie matérialiste de marchée des uns et à la volonté insatiable de controle totalotaire des autres, elle est apparue plus que jamais porteuse d'une rationalité critique: elle redécouvrait ainsi l'identité philosophique qui l'habite et la pousse à soumettre son devenir à la raison.

Mais elle affronte aujourd'hui cet enjeu en devant reconnaître que les faillites de l'Est et de l'Ouest sont, elles aussi, les fruits de sa propre modernite. Sa volonté de rationalisation a beau avoir conduit l'homme à la maîtrise du monde, le désir de maîtrise éthique et politique de soi qu'elle nourrissait ne semble avoir rencontré que des échecs massifs. L'identité du vouloir de vérité qui anime son expérimentation du savoir, de la puissance et de la sagesse paraît illusoire et semble n'avoir toujours masqué qu'une volonté de puissance. Ces faillites ne feraient que mettre au jour sa folie latente.

Ce qui la rend apte à reconnaître cette folie comme telle et à la surmonter demeure pourtant cette raison philosophique qui la voue à mettre la mémoire vive de son jugement à l'epreuve de ces experiences mortelles. Aussi la reprise du voeu européem de constituer une unité politique ne peut-elle intégrer aujourd'huicomme il se doit la pluralisme des nations et des cultures, elle ne peut intégrer l'expérience douloureuse de ces divers échecs qu'en interrogeant l'identite philosophique qui la porte.

\title{
VIENT DE PARATTRE
}

Aristote politique. Etudes sur la politique d'Aristote. Sous la direction de P. Aubenque et A.Tordesillas. Paris: PUF, 1993.

CHALLEMEL-LACOUR. Etudes et réflexions d'un pessimiste. Paris: Fayard, (1862), 1993.

FOLSCHELD, DOMINIQUE. La philosophie allemande de Kant à Heidegger. Paris: PUF, 1993.

GLAZIOU, YVES. Hobbes en France. Paris: PUF, 1993.

HARRIS, JAMES F. Against Relativism: A Philosophical Defense of Method. La Salle, Illinois : Open Court, 1992.

LONGUENESSE, BEATRICE. Kant et le pouvoir de juger. Paris: PUF, 1993. 